\title{
"Do que vocês estão falando?": ressonâncias formais e políticas de uma dramaturgia do convívio
}

"What are you talking about?":

political and formal resonances of a conviviality dramaturgy

\section{Luciana Eastwood Romagnolli}

Luciana Eastwood Romagnolli

Doutoranda no Programa de Pós-Graduação em Artes Cênicas da Escola de Comunicações e Artes da Universidade de São Paulo. Jornalista e crítica de teatro.

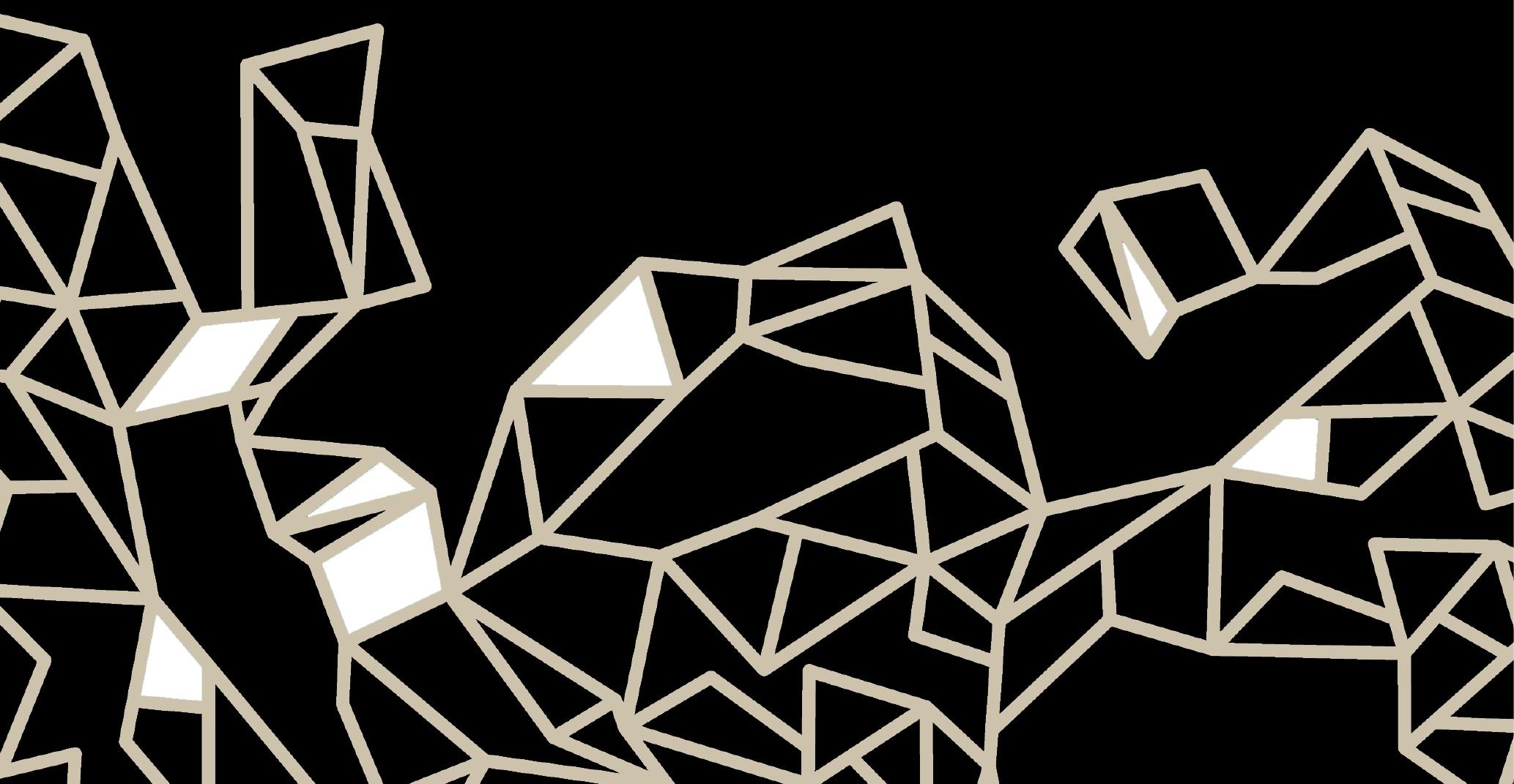




\section{Resumo}

Este artigo propõe-se a uma revisão crítica da obra do diretor Marcio Abreu em diálogo com os conceitos de convívio (DUBATTI, 2007) e situação (CORNAGO, 2016), a partir da análise de três espetáculos dos quais assina a dramaturgia: Vida (2010) e PROJETO bRASIL (2015), com a companhia brasileira de teatro, e Nós (2016), com o grupo Galpão, além de ecos das experiências de encenação de textos de autores franceses - Suíte 1 de Philippe Minyana (2004); Apenas o fim do mundo de Jean-Luc Lagarce (2006); e Isso te interessa? de Noëlle Renaude (2011) - e de um autor russo - Oxigênio de Ivan Viripaev (2010) -, para identificar procedimentos, formas e questões em ressonância que tangenciem uma política do convívio.

Palavras-chave: Convívio, Dramaturgia, Situação.

\section{Abstract}

This article proposes a critical review of Marcio Abreu's work in dialogue with the concepts of conviviality (DUBATTI, 2007) and situation (CORNA$\mathrm{GO}, 2016)$, based on the analysis of three performances written by him: Life (2010) and PROJETO bRASIL (2015), from companhia brasileira de teatro, and We (2016), from Grupo Galpão, and echoes of the experiences of staging French writers - Suite 1 by Philippe Minyana (2004); It's Only the End of the World by Jean-Luc Lagarce (2006); and Bon, Saint Cloud by Noëlle Renaude (2011) - and a Russian writer called Ivan Viripaev who wrote Oxygen ( 2010). The purpose is to identify procedures, forms and issues in resonance, which approaches a conviviality policy. Keywords: Conviviality, Dramaturgy, Situation.

\section{Introdução}

Há objetos artísticos que convidam à revisão - e à reinterpretação - de toda a obra de um criador. O encontro do dramaturgo e diretor Marcio Abreu (PR/RJ) com o Grupo Galpão (MG) para a elaboração do espetáculo Nós, que estreou em abril de 2016 no Galpão Cine Horto, em Belo Horizonte, é desses que trazem à tona particularidades dos diferentes artistas envolvidos e propiciam uma renovação do olhar sobre eles. Isso é possível por ser um 
trabalho forjado no encontro das diferenças, em que Abreu emprega sua poética considerando as especificidades do conjunto de pessoas com as quais desenvolve um processo de criação. No trabalho artesanal de Nós, o encenador enfrentou as idiossincrasias de um grupo de teatro formado por doze integrantes, dos quais sete estão em cena, e com 34 anos de história.

A dramaturgia, assinada por Abreu e Eduardo Moreira, retrabalha disruptivamente essa matéria biográfica relativa ao convívio dentro de um coletivo, contemplando a intimidade, as divergências, o envelhecimento e a estagnação, de modo que as questões internas recebem tratamento ambíguo para refletirem também problemas políticos contemporâneos. A inércia, seja a do artista ou a do sujeito político, emerge como um dos temas reincidentes e é confrontada pela proposta de um registro de atuação estranho à trajetória representativa do grupo mineiro, fundado no corpo performativo, na evidenciação da presença e no embaraço entre real e ficcional. Nesse jogo de espelhos entre o microcosmo ficcional e o macrocosmo social, forja-se um emaranhado de sentidos potenciais a ser desdobrado pela apreensão de cada espectador, o que devolve ao Galpão uma potência crítica e de afetação sensória tal como há algum tempo seus trabalhos não apresentavam e numa forma inédita para o grupo, que conjuga representação, ação e situação, como "três níveis que convivem como parte de um fenômeno cênico e de um contexto cultural" (CORNAGO, 2016, p. 22).

O auge dessa dramaturgia é a sequência da expulsão da atriz Teuda Bara pelos demais atores, construída a partir de uma representação da inatividade da mulher que vemos em cena sempre sentada, pouco contribuindo para a feitura da sopa e derramando repetidamente um copo de água para o incômodo dos outros que tentam fazer a refeição. A retirada à força da atriz aponta para os problemas do envelhecimento e do descarte, da exclusão do outro, e abre ainda uma possibilidade de leitura política diretamente relacionada ao impeachment da presidenta Dilma Rousseff. Camadas de sentido instáveis avançam sobre a esfera privada e a pública, a artística e a política.

Por outro lado, Nós revela muito dos caminhos criativos de Marcio Abreu. O deslocamento do dramaturgo e diretor para o trabalho com outro grupo permite perceber, sob uma perspectiva distinta, procedimentos centrais de sua poética desenvolvida à frente da companhia brasileira de teatro desde 2000. Em especial, quando relacionados a outros dois espetáculos cuja dramaturgia, 
sempre criada coletivamente com os atores e as atrizes envolvidos no processo, é assinada por Abreu com sua companhia: Vida de 2010, e PROJETO bRASIL, cuja pré-estreia ocorreu em setembro de 20151. A partir das duas criações mais recentes, é possível rever a trajetória teatral do encenador pela perspectiva proposta por Oscar Cornago (2016), teórico espanhol que investiga a transição do foco no teatro performativo no fim do século XX para a atenção sobre a experiência do espectador como sujeito num teatro de situação neste início do século XXI. A partir dessas discussões, é possível considerar questões estéticas, éticas e políticas que a convivência humana - seja numa família, banda, grupo de teatro, acontecimento teatral, cidade ou país - suscita na dramaturgia, apontando para o dentro e o fora do teatro.

Das tantas maneiras possíveis de olhar para o teatro de Marcio Abreu, destacaremos questões relativas ao convívio, característica basilar do teatro como local onde ocorre a copresença de corpos de atores, técnicos e espectadores no mesmo espaço e tempo (DUBATTI, 2007), e que vem sendo dramaturgicamente valorizada e problematizada nas criações do encenador (ROMAGNOLLI, 2013; 2014). Em outras palavras, o "estar junto" como reafirmação da qualidade intersubjetiva das práticas cênicas e como configuração privilegiada para a circulação dos afetos, a reflexão sobre a vida em sociedade e a possibilidade de ações políticas coletivas de um teatro de situação cuja abrangência expandida contempla a dimensão do espectador e o contexto social. Em síntese, cada um a seu modo, os trabalhos criativos de Abreu parecem indagar: como conviver?

Tanto em Nós como em Vida e em PROJETO bRASIL, as dramaturgias instauram situações de apresentação, evidenciadas pela constituição de uma banda em cena pelos atores, convocando para o teatro a qualidade performática do show musical, cuja relação temporal se dá no presente, numa zona de intensa circulação de energia e afetos. Tal estratégia ecoa outro espetáculo do diretor, Oxigênio (2010), com texto do dramaturgo russo Ivan Viripaev. "Este é um ato que deve ser produzido aqui e agora,' diz o ator Rodrigo Bolzan para

1 Vida tem atuações de Giovana Soar, Nadja Naira e Rodrigo Ferrarini, cenário de Fernando Marés e luz de Nadja Naira. PROJETO bRASIL tem atuações de Giovana Soar, Nadja Naira, Rodrigo Bolzan e do músico Felipe Storino; cenário de Fernando Marés e luz de Nadja Naira. Nós tem atuações de Antonio Edson, Chico Pelúcio, Eduardo Moreira, Júlio Maciel, Lydia Del Picchia, Paulo André e Teuda Bara; cenário de Marcelo Alvarenga e luz de Nadja Naira. 
abrir a apresentação, forjada como um show de rock, num palco com cortina e microfone. A apresentação - ainda que inserida em uma narrativa fabular, como a celebração do aniversário da cidade, em Vida - configura-se como estratégia para reforçar a percepção das presenças compartilhadas.

Relacionada à dimensão da materialidade e do corpo fenomênico (FISCHER-LICHTE, 2008) e ao tempo e ao espaço real compartilhados por atores e espectadores, a ênfase na apresentação, portanto, "busca restituir ao teatro sua concreta materialidade como acontecimento" da cultura vivente (DUBATTI, 2007, p. 22), explorando as tensões e instabilidades entre os planos representacional e presentacional, "quer dizer, dos níveis de semiotização à ordem convival" (DUBATTI, 2007, p. 113). Considerando, como Lehmann (2007), que no teatro "ocorre um entrecruzamento único de vida real cotidiana e de vida esteticamente organizada" (p. 18) e, como Cornago (2016), que o teatro do século XXI enfatiza a situação na medida em que "a obra se coloca em relação a uma série de fatores que a rodeiam" e expõe um contexto mais amplo ( $p$. 22-23), é justamente a potência disruptiva como experiência sensível e crítica desse entrecruzamento entre o estético e o social, a representação e o real que está em jogo.

Em todos esses casos, há nessa opção pela evidenciação da apresentação, da situação e do convívio um viés político, que a frase de Ivan Viripaev parece desvendar: é no aqui e agora da copresença dos corpos que se produz o ato, ou seja, que é possível agir, afetar e transformar a si e aos outros. "Talvez seja impossível mudar o mundo. Talvez o caminho seja começar por nós mesmos", diz, por sua vez, Eduardo Moreira em Nós, indiciando uma operação micropolítica que se manifesta, no teatro de Abreu, na sensibilização recíproca, na invenção de formas e na reflexão sobre a linguagem, sobre os afetos, sobre a convivência e a política entre aqueles que "estão juntos" - essas microcomunidades heterogêneas e temporárias que o teatro potencialmente forma.

Lugar onde estar com outras pessoas para uma experiência estética extracotidiana, o teatro torna-se essa zona de experiência de uma percepção e de uma sensibilidade dilatadas no contrafluxo do condicionamento perceptivo do capitalismo tardio (CRARY, 2014). Constitui-se, assim, uma política da percepção, conforme sugerido por Lehmann (2007), que consiste no investi- 
mento em uma "desalienação perceptiva" a partir do deslocamento perceptivo do espectador pelos trânsitos desestabilizadores entre palco e plateia e na tomada de consciência do espectador sobre si mesmo.

\section{Escavação da língua para uma tentativa de diálogo}

A essa dimensão básica do convívio no acontecimento teatral soma-se outra que é sua tematização na dramaturgia, calcada nas relações intersubjetivas desenvolvidas entre os performers mais ou menos investidos de ficcionalidade. Em sua definição de convívio teatral, Dubatti observa que este implica um rito de sociabilidade compartilhado, de reconhecimento de si mesmo e da alteridade, que permita a mútua afetação em condições de proximidade e audibilidade. Em Vida e Nós, em especial, essa dimensão da sociabilidade compartilhada é problematizada em cena. A banda formada pelo Galpão canta Lama, canção mais conhecida nas vozes de Ângela Maria e Maria Bethânia, cuja letra indica duas forças concorrentes: a afirmação da individualidade ("se eu quiser fumar, eu fumo/ se eu quiser beber, eu bebo") em contraposição à percepção do convívio ("comendo a mesma comida, bebendo a mesma bebida, respirando o mesmo ar"), que aponta para a alteridade. O equilíbrio entre essas duas instâncias, a pessoal e a coletiva, é chave para a vida em grupo de teatro e em sociedade.

O disparador comum aos dois espetáculos, então, é a reunião de pessoas para realizar uma ação conjunta; a diferença está na natureza da relação entre aquelas pessoas: Vida reúne quatro figuras2 desconhecidas entre si e que precisam conviver por ocasião dos ensaios para uma apresentação musical em celebração ao jubileu da cidade, tempo durante o qual travam tentativas de diálogo como meio de "percorrer a distância até o outro, seu desconhecido e semelhante"3 Enquanto isso, Nós é um encontro

2 Essas "figuras" que povoam Vida não se constituem como personagens clássicos, respondem pelos nomes dos próprios atores e absorvem particularidades físicas, comportamentais e biográficas destes, mas tampouco se confundem com os próprios atores por estarem imersos na representação ficcional. A proposta de Nós é semelhante na medida em que os atores do grupo Galpão atendem pelos próprios nomes e dilatam características pessoais dentro da ficção engendrada. Em ambos os trabalhos há momentos de investimento maior na performance dos corpos fenomênicos, reduzindo a mediação ficcional.

3 Ver crítica de Vida: ROMAGNOLLI, L. Uma Tentativa de Diálogo. In: Questão de crítica, 2010. Disponível em: <http://www.questaodecritica.com.br/2010/05/uma-tentativa-de-dia- 
de velhos conhecidos que já compartilham uma história juntos e, no presente da ação cênica, preparam uma sopa. Ambos tratam das dificuldades e delicadezas das relações interpessoais nos extremos da intimidade e da falta dela, com suas hesitações, fracassos e obsessões. Os diálogos travados são da ordem da conversação, atacando a retórica e os sentidos unívocos; se em Vida mantêm certa linearidade, esvaziados porém de conflito, em Nós, desconstroem-se em uma espiral de repetições que desata as réplicas e remaneja os sentidos. "Do que vocês estão falando?”, pergunta insistentemente Teuda Bara em Nós, como quem chama a atenção do espectador para ouvir além da primeira camada de sentido. "Resta ao leitor encontrar seu caminho entre essa superfície banal e o jogo das profundezas" (RYNGAERT, 1998, p. 23). Cabe ao espectador a operação mental de deixar as linhas conversacionais ressoarem e entrechocarem-se até que outros sentidos ascendam.

Tais procedimentos de escrita e estruturação dialogam com a dramaturgia francesa contemporânea, com a qual Marcio Abreu familiarizou-se ao encenar Suíte 1 (2004) de Phillipe Minyana, dramaturgo que já disse escrever "contra palavras cansadas"4 compondo "objetos sonoros" (CORVIN, 2000) em que predomina a musicalidade do fraseado e a atenção volta-se a como o diálogo humano acontece; Apenas o fim do mundo (2006), no qual Jean-Luc Lagarce empilha uma instabilidade de tempos verbais que adiam a ação e convidam-nos a ouvir o que se oculta por trás das palavras e a própria dificuldade de dizê-las; Isso te interessa? (2011) de Noëlle Renaud, com suas contrações temporais e oscilações entre a fala subjetiva e a épica, mediante a emergência das rubricas; e, finalmente, o mais distinto desse grupo pela composição psicológica dos personagens, Esta criança (2012), de Joël Pommerat, com seus cortes de cenas nos picos dos conflitos. Constituem-se mais ou menos como teatros da conversação, da interação comunicacional, voltados à "encenação da fala, liberada do peso dos personagens", conforme Jean-Pierre Ryngaert (1998) analisa justamente a partir de um recorte do teatro contemporâneo francês:

logo/>. Acesso em: 30 set. 2016

4 Citação de Minyana retiradas do site da companhia brasileira de teatro em <http://www. companhiabrasileira.art.br/suite/ >. Acesso em: 21 abr. 2016. 
Se o interesse do diálogo não se encontra no que é dito e o sentido nos enunciados, deve-se procurá-lo na maneira como as coisas são ditas, nas entonações, nas hesitações, nos silêncios, nos suspiros, na moderação, no exercício performativo da linguagem e, de um ponto de vista teórico, na pragmática que estuda o caráter factual da fala. (p. 151)

Esse teatro que trabalha com a "escavação da língua" e o "adiamento do sentido", como Abreu define a operação de Lagarce em Apenas o fim do mundo, e com uma concepção de dramaturgia que pressupõe a autonomia da linguagem, é também o território estético do PROJETO bRASIL. A diferença está no redirecionamento do diálogo do eixo intraficcional para o extraficcional, ou seja, as relações intersubjetivas dominantes neste espetáculo são as que ocorrem entre palco e plateia. Além disso, trata-se do trabalho cuja força discursiva diretamente responsiva a fatos recentes noticiados no país e no exterior é ímpar na obra do diretor Marcio Abreu - um engajamento poético-político com o real do qual só se aproxima de Nós justamente a criação seguinte. No espetáculo com o Galpão, a violência policial contra o negro ("corpo morto de cinco meninos negros fuzilados pela polícia") é problematizada, somada a um manifesto contra a inércia, a números de refugiados e das "276 meninas sequestradas e estupradas" na Nigéria, que se inscrevem nos corpos nus de Eduardo Moreira e Teuda Bara. Dados do real atravessados por versos do Monólogo do Veneno de Gota D'Água, de Chico Buarque, e pelos ecos da Lama antes cantada, formando um retrato expressionista de uma realidade violenta.

Mesmo em Maré5, texto de Abreu que compõe o espetáculo Real (2015) do grupo Espanca! (MG), embora o pretexto que desencadeou a escrita seja um fato real - a chacina no Complexo da Maré - que aparece na peça curta, o tratamento poético afasta-se do campo dos discursos diretos em favor de uma elaboração mais poética. Assim, Nós e PROJETO bRASIL inauguram no trabalho de Abreu outros modos de relação com o contexto político do país a partir da emergência de forças reacionárias e antidemocráticas, que passam a afetar a poética do artista sem descaracterizá-la. PROJETO bRASIL

5 Peça curta publicada com o texto de PROJETO bRASIL pela editora Cobogó em 2016 (ABREU, M. Marél PROJETO bRASIL. Rio de Janeiro: Cobogó, 2016). Maré foi encomendada pelo grupo Espanca! para formar, com outras peças curtas escritas por Roberto Alvim, Diogo Liberano e Byron O’Neil, o espetáculo Real (2015). 
abre-se como palco-palanque para as palavras de José Mujica (ex-presidente uruguaio) e de Christiane Taubira (ex-ministra da Justiça francesa); palco-paisagem do primitivismo e da violência expressos em imagens em movimento; palco poético onde as palavras se desestabilizam, e a língua portuguesa fraqueja no contrassenso dadaísta das letras cantadas por Felipe Storino ou na desintegração e reconstrução de sentidos pela voz de Rodrigo Bolzan. Formalizações distintas tangenciam uma concepção de país, sem nunca representá-lo, como Vida tangencia uma ideia de cidade sem restringir-se a representá-la. PROJETO bRASIL move-se no sentido de superação de uma versão do Brasil ultrapassada ética, social e politicamente.

O endereçamento das palavras e ações, mais do que nunca nas criações de Abreu, dirige-se para além do palco. À dimensão do convívio dramaturgicamente pautado dentro da cena soma-se então a problematização do convívio entre palco e plateia, ator e espectador, que é um aspecto central nas composições dramatúrgicas do dramaturgo já desde Vida, pelo menos, mas assume nova configuração e força política em PROJETO bRASIL. Naquele espetáculo de 2010, Rodrigo Ferrarini assumia a função de fazer o convite diretamente aos espectadores tanto pelo direcionamento quanto pelo conteúdo de sua fala - por exemplo, quando trata do "reconhecimento da diferença entre o eu que eu sou e o eu que o outro é". Ele prossegue: "Separados e próximos. Perceberam?" (ABREU, 2015). Ao dizer "separados", o ator aponta com o braço a distância entre ele e a atriz Giovana Soar (intraficcional). Ao dizer "próximos", aponta para a distância entre si e os espectadores (extraficcional), visivelmente menor do que a outra. Esse jogo permeia todo o transcorrer de Vida como gesto de implicação do espectador no acontecimento teatral e nas reflexões propostas acerca das relações dialógicas/comunicacionais e de atribuição de sentidos ao mundo. Assim, sem desfazer a distância entre aqueles que atuam e aqueles que observam, o público é chamado a "fazer-se consciente da situação da qual está participando" e, além de ver, perceber-se como "parte dessa situação de percepção" (CORNAGO, 2016, p. 23-29). Disso decorre outra relação que não somente a identificação ensimesmada racional/intelectual, embora esta ainda provavelmente prepondere. 
Nós e PROJETO bRASIL avançam na construção de situações que incluem o espectador expandindo o olhar do palco como lugar autônomo para o acontecimento teatral que se realiza na relação com a plateia. Nesse sentido, aproximam-se mais dos dois espetáculos da Companhia Brasileira dirigidos não por Marcio Abreu, mas por Giovana Soar e Nadja Naira: A viagem (2009) e A cidade sem mar (2016). Ambos constituem as experiências mais radicais de participação do espectador empreendidas pela Companhia mediante as questões que Cornago (2016) assim elabora: "Como conciliar a coerência interna da obra enquanto sistema próprio com a necessidade de fazê-la frente a um público? Como estabelecer a relação entre autonomia e dependência?" (p. 29). Enquanto Abreu abre a dramaturgia para a inclusão da presença consciente dos espectadores, mantendo, contudo, um grau elevado de autonomia do sistema de signos que compõe em cena, as duas outras integrantes da Companhia Brasileira propõem dispositivos em ampla dependência da participação do espectador para constituição dos sentidos.

A viagem,6 sobretudo, faz do espectador um cocriador de dramaturgia. Baseado no espetáculo Viagem em terra interior, da diretora francesa Léa Dant, do qual Giovana Soar participou como atriz no Festival Internacional de São José do Rio Preto em 2003, o dispositivo foi remontado com atores paranaenses convidados a elaborar dramaturgias próprias, que incluíssem a exploração sensorial do espaço e uma relação com o espectador. Este é vendado e, às cegas e individualmente, acompanha um único ator investido de seu personagem, que lhe conduz pelo espaço cênico enquanto narra uma história instigando a imaginação e o diálogo, na tentativa de instaurar um vínculo e uma vivência comum. Permanece a distância entre espectador e ator, uma vez que este dá os comandos àquele, cuja ação obedece ainda a códigos, embora distintos do teatro convencional, sugeridos pela condução do ator. Entretanto, o papel do espectador transforma-se, rompida a identificação distanciada, ensimesmada e predominantemente intelectual em troca de uma experiência corporificada. Eis uma proposta que depende completamente de espectadores disponíveis a entrar no jogo para realizar-se.

6 Ver ROMAGNOLLI, L. Intimidade entre estranhos. In: Gazeta do Povo, 2009. Disponível em: <http://www.gazetadopovo.com.br/caderno-g/intimidade-entre-estranhos-br32aphlddmk2fg2brdissfv2>. 
A cidade sem mar foi criada a partir da obra do dramaturgo Manoel Carlos Karam para a Curitiba Mostra, projeto que envolveu quatro companhias na encenação de espetáculos baseados em escritores e escritoras da cidade para serem apresentados no Festival de Teatro de Curitiba 2016. A dramaturgia investe em um percurso pela cidade, primeiramente ficcional, até o deslocamento geográfico de fato. De início, Nina Ribas, na função ficcional de produtora, apresenta características da rua em frente ao teatro, inscrevendo-o na geografia e na história da cidade. A partir daí, os espectadores cumprem um trajeto atravessado por personagens: a fila onde somos convidados a preencher um formulário, os bancos onde esperamos a partida, a sala ocupada por guarda-sóis onde assistimos ao vídeo com imagens do mar e, enfim, a entrada em um ônibus intermunicipal com destino ao litoral paranaense, mas que roda pelo centro da cidade deslocando o olhar do espectador para uma cena que se constrói no ponto de ônibus, o que gera uma ficcionalização da experiência da cidade, na qual - mais uma vez - o espectador está incluído, além de observador, como habitante, cidadão, sujeito político. Sobre esse tipo de formulação, diz Cornago (2016):

Abrir a construção do sensível ao sujeito da percepção implica situar-se em um meio aberto, que não controlamos, e aceitar o desconhecimento que isso produz, uma situação na qual nada vai acabar saindo exatamente como se espera, se ao público é oferecido realmente o espaço para intervir com certa liberdade. Esta é a potência e, ao mesmo tempo, o risco de expor-se ao olhar do outro quando este é convidado realmente a participar de uma construção que, na medida em que opera com o outro, faz coincidir o estético com o social (p. 29-30).

Retornemos às encenações de Marcio Abreu e seu balanço entre a cena autônoma e a inclusão do espectador como sujeito, tensionando o estético e o social aos quais se refere Cornago. Em Nós a observação estética do convívio entre os atores do grupo Galpão amplia-se para a percepção do convívio amplo que abrange a dimensão social da apresentação, não somente nos já referidos versos entoados por Teuda Bara ou quando Chico Pelúcio fotografa a plateia ou quando a caipirinha é servida ao público. A sequência em que essa estratégia atinge outras implicações sociais mais contundentes vem logo após a expulsão de Teuda, física e simbolicamente 
violenta, quando a sopa preparada pelo grupo é enfim oferecida e servida aos espectadores. $\mathrm{O}$ que $\mathrm{o}$ ato de tomar a sopa implica? A dimensão da recepção é sempre fugitiva, instável, individual, portanto, generalizar é uma operação difícil, mas uma possibilidade de apreensão é instaurar um incômodo ético que coloca o espectador em posição de escolher se aceita o que o grupo que acabou de expulsar aquela mulher lhe oferece, desfruta do prazer da sopa e, caso o faça, esquece o mal-estar da expulsão ou engole-o às colheradas, ou recusa o alimento. Desse modo, a dramaturgia põe o público em posição de questionamento e decisão, da qual cada espectador poderá ou não se ocupar, dependendo do seu processo de atribuição de sentidos e do quanto se dispõe a entrar ou não no jogo proposto, do quanto é conduzido e do quanto pondera criticamente sobre seu papel no acontecimento teatral.

Em PROJETO bRASIL, a inclusão do espectador é revelada desde antes do início propriamente dito. A rubrica indica aos atores: "Incluem as pessoas, o público que chega. Oferecem cachaça. Cruzam de maneira incomum o espaço da plateia. Circulam por entre as poltronas e as pessoas. [...] Convivem" (ABREU, 2016). Em seguida, a fala de Rodrigo Bolzan enuncia reiteradamente a relação de convívio: "Eu gostaria de agradecer primeiro a chance que eu recebi de estar aqui diante de vocês, [...] ter que dizer pra vocês, diante de vocês, para vocês" (Id.). Nessas ações, reside um movimento de instaurar uma situação que abranja o território estético, ficcional, do palco, e o terreno social, real, do público - embora essas duas dimensões se contaminem, criando uma zona liminar. Situação que, para Cornago (2016), "supõe um momento de reflexão compartilhada e no tempo presente sobre o que está ocorrendo. Assim como a ação, apela ao interlocutor da obra, mas para propor-lhe um campo de discussão sobre um projeto artístico e social". (p. 22)

A cena-chave para que a reflexão partilhada se estabeleça unindo a experiência corpórea à estimulação lógico-racional é disparada por Nadja Naira e Rodrigo Bolzan durante o discurso (originalmente proferido por Taubira) de reconhecimento da igualdade de direitos entre casais hetero e homossexuais, ouvido em off nas vozes dos dois enquanto se beijam e, aos poucos, avançam sobre os espectadores para beijarem pessoas do mesmo sexo ou do oposto. Assim, 
[...] buscam na plateia outros beijos políticos, afirmativos da naturalidade do encontro entre duas bocas quaisquer e, sobretudo, do direito de duas bocas quaisquer e de dois corpos quaisquer e de dois sujeitos quaisquer à relação amorosa e à instituição laica do casamento. (ROMAGNOLLI, 2016).

A cada apresentação tal proposta se concretizará de modo único, de acordo com os diferentes espectadores que tomam parte do acontecimento. Os atores já experimentaram recusas silenciosas, como o virar do rosto, ou aos brados, e foram acolhidos de diversas formas, incluindo ocasiões em que o beijaço continuou pela plateia. Novamente, só a cada apresentação e a depender da disponibilidade dos espectadores de entrar no jogo é que o dispositivo se efetiva como experiência ou não. Quando sim, "há nessa concretização do discurso em ato compartilhado um gesto que avança para além da retórica até uma experiência psicofísica, que se constitua numa afetação produtora de outra ordem de saber" (ROMAGNOLLI, 2016). Para alguns, uma experiência desmitificadora do beijo entre pessoas do mesmo sexo; para outros, a efetivação de um manifesto político de apoio à igualdade de direitos independentemente de orientação sexual.

Conforme já observado no posfácio da publicação do texto:

A condução dramatúrgica para isso é, e precisa ser, minuciosamente cuidadosa, de modo que o convite ao beijo político não se faça invasão, mas política do afeto. Tampouco se constitui como celebração comunitária ingênua, e, para isso, a cena seguinte é determinante: as imagens de violência da invasão do corpo da mulher pelo homem evocam as frágeis condições de intimidade e consentimento numa sociedade misógina, manchada pela cultura do estupro (ROMAGNOLLI, 2016).

Desse modo, PROJETO bRASIL demanda do espectador um posicionamento ético, político e afetivo pelo ato (efetivado ou recusado), implicando seu corpo na construção dramatúrgica mediante um dispositivo convivial, que "torna visível o contexto espetacular em torno da obra, isto é, a situação em que ela é produzida" (CORNAGO, 2016, p. 23): uma apresentação teatral que toma lugar em um determinado teatro, produzida por atores diante de espectadores, em um contexto social de homofobia e outros preconceitos que 
restringem os direitos civis de grande parcela dos cidadãos e respondem por índices elevados de violência urbana.

Mesmo quando age - beija - o público não deixa de ser público. O dispositivo do beijaço coloca o espectador como sujeito da ação, ao mesmo tempo - como observa Cornago - que é posto como objeto do olhar dos outros espectadores, pois quem beija ou recusa é observado pelos demais componentes do público. Diz Cornago (2016):

Se agora aplicamos esse efeito de deslocamento sobre o público, este deixaria de ser unicamente o sujeito da percepção para converter-se também em objeto que se oferece para ser percebido pelos demais. Isso produz a consequente sensação de desestabilização, de questionamento ou dissolução dos limites que protegem sua identidade como público e que o obrigam a assumir social e esteticamente aquelas dimensões que já não ficam ocultas atrás de sua condição de espectador. (p. 30)

Com esses dispositivos conviviais agenciados num teatro de situação, o espectador envolve-se corporalmente na elaboração estética da qual toma parte, somando à apreensão lógico-racional uma experiência perceptiva distinta, que afetará os sentidos produzíveis. Sua atenção é reconduzida oscilantemente para a cena e para a plateia, e sua identidade é convocada para assumir uma responsabilidade e uma possibilidade de ação. À distinção do projeto moderno, essas propostas cênicas pretendam não somente acentuar a sensibilidade a uma situação no tempo presente, mas também colocar o espectador nessa posição instável de sujeito (da ação) e objeto (do olhar do outro espectador quando age), para que, "tomando consciência de sua condição de público, considere a representação social da qual está participando" (CORNAGO, 2016, p. 39). Diante de um sistema político representacional faIho, vêm lembrar-nos de que somos nós os representados e os responsáveis por transformar os contextos dos quais tomamos parte. Assim, numa situação de convívio, o comum partilhado entre um grupo heterogêneo e temporário de pessoas abre a possibilidade da construção de sujeitos coletivos capazes de realizar outras ações reais ou imaginárias, harmônicas ou conflituosas, por vezes falhas e esvaziadas, por vezes efetivas. 


\section{Referências bibliográficas}

ABREU, M. Maré/ PROJETO bRASIL. Rio de Janeiro: Cobogó, 2016.

Vida. Ensaia: revista de dramaturgia, performance e escritas múltiplas, [S.I.], n. 1, dez. 2015. Disponível em: <http://www.revistaensaia.com/vida>. Acesso em: 30 set. 2016.

CORNAGO, Ó. Y despues de la performance qué? Público y teatralidad a comienzos del siglo XXI. Urdimento, Florianópolis, v. 1, n. 26, p. 20-41, 2016.

CORVIN, M. Philippe Minyana, ou la parole visible. Paris: Theatrales, 2000.

CRARY, J. 24/7: capitalismo tardio e os fins do sono. São Paulo: Cosac Naify, 2014. DESGRANGES, F. A inversão da olhadela. São Paulo: Hucitec, 2012.

DUBATTI, J. Filosofia del Teatro I: convivio, experiencia, subjetividade. Buenos Aires: Atuel, 2007.

FISCHER-LICHTE, E. The transformative power of performance: a new aesthetics. Translation Saskya Iris Jain. London; New York: Routledge, 2008.

LEHMANN, H. T. Teatro pós-dramático. São Paulo: Cosac Naify, 2007.

ROMAGNOLLI, L. R. Convívio e presença como dramaturgia: a dimensão da materialidade e do encontro nas criações da companhia brasileira de teatro. Belo Horizonte: UFMG, 2013. p. 16.

Convívio e presença como dramaturgia: a dimensão da materialidade e do encontro em Vida. Sala Preta, São Paulo, v. 14, n. 2, p. 85-94, 2014.

. Marés brasileiras: discursos em contrafluxo. In: ABREU, M. Maré/ PROJETO bRASIL. Rio de Janeiro: Cobogó, 2016.

RYNGAERT, J. P. Ler o teatro contemporâneo. Martins Fontes: São Paulo, 1998. SARRAZAC, J. P. Léxico do drama moderno e contemporâneo. São Paulo: Cosac Naify, 2014.

Recebido em 24/09/2016

Aprovado em 28/10/2016

Publicado em 21/12/2016 